\title{
Sobrevivência de espécies nativas em função da calagem em área degradada na bacia
}

\section{do Rio Pandeiros}

\author{
Survival of native species in the function of liming in a degraded area in the Pandeiros Watershed \\ Supervivencia de especies nativas por encalamiento en zona degradada de la cuenca del Río
}

\section{Pandeiros}

Recebido: 04/08/2021 | Revisado: 12/08/2021 | Aceito: 16/08/2021 | Publicado: 18/08/2021

Pablo Fernando Santos Alves

ORCID: https://orcid.org/0000-0001-9715-9111 Universidade Federal de Minas Gerais, Brasil

E-mail: pablofernando.agro@gmail.com

Marcos Koiti Kondo

ORCID: https://orcid.org/0000-0001-6875-4907 Universidade Estadual de Montes Claros, Brasil

E-mail: marcos.kondo@unimontes.br

Verônica Godinho Ferreira

ORCID: https://orcid.org/0000-0002-4344-8222 Universidade Estadual de Montes Claros, Brasil

E-mail: veronica.agrounimontes@gmail.com

David Gabriel Campos Pereira

ORCID: https://orcid.org/0000-0001-8977-7091 Universidade Estadual de Montes Claros, Brasil

E-mail:david.campos.pereira@ hotmail.com

Silvânio Rodrigues dos Santos

ORCID: https://orcid.org/0000-0002-5431-1205 Universidade Estadual de Montes Claros, Brasil E-mail: silvanio.santos@unimontes.br

Regynaldo Arruda Sampaio

ORCID: https://orcid.org/0000-0003-3214-6111

Universidade Federal de Minas Gerais, Brasil E-mail: rsampaio@ufmg.br

\begin{abstract}
Resumo
Objetivou-se avaliar o índice de sobrevivência de espécies nativas do cerrado em função da calagem. O experimento foi realizado em uma microbacia do rio Pandeiros. A área experimental apresentava solo com baixo $\mathrm{pH}$, baixa saturação por bases e fortes sinais de degradação antrópica. Na área de empréstimo à montante de terraços construídos com a finalidade de conter a erosão foi realizado o plantio de espécies florestais nativas pioneiras e não pioneiras, testando a ausência e a presença de calcário dolomítico nas covas de plantio. O plantio foi realizado em duas subáreas dentro da microbacia. Para a subárea 1, as espécies pioneiras testadas foram o Angico Vermelho (Anadenanthera macrocarpa), Aroeira (Lithraea molleoides) e Pau Ferro (Caesalpinia ferrea); já para a subárea 2 as espécies testadas foram: Gonçalo Alves (Astronium fraxinifolium), Carne de Vaca (Clethra scabra) e Farinha Seca (Albizia hasslerii). As espécies secundárias inicial e não-pioneira plantadas entre as espécies pioneiras foram respectivamente o Ipê Amarelo (Tabebuia ocharea) e o Jatobá (Hymenaea courbaril), sendo utilizadas essas espécies para as subáreas. Após 449 dias foi a avaliado o índice de sobrevivência das espécies pioneiras e não pioneiras para as subáreas 1 e 2 . De maneira geral não se verificou efeito da calagem na sobrevivência de plantas. Para a subárea 1, a espécie com maior índice de sobrevivência foi o Pau Ferro. Para a subárea 2, a espécie com maior índice de sobrevivência foi o Gonçalo Alves. A subárea 1 apresentou maior índice de sobrevivência de espécies não pioneiras que a subárea 2.
\end{abstract}

Palavras-chave: Erosão; Cerrado; Acidez; Reflorestamento.

\begin{abstract}
The aim of this study was to evaluate the survival rate of native cerrado species as a function of liming. The experiment was carried out in a Pandeiros river watershed. The experimental area presented soil with low $\mathrm{pH}$, low base saturation and strong signs of anthropic degradation. In the area of lending up terraces built to contain erosion, we planted pioneer and non - pioneer native forest species, testing the absence and presence of dolomitic limestone in the planting pits. Planting was carried out in two subareas within the microbasin. For subarea 1 the pioneer species tested were Angico Vermelho (Anadenanthera macrocarpa), Aroeira (Lithraea molleoides) and Pau Ferro (Caesalpinia ferrea); the species tested were: Gonçalo Alves (Astronium fraxinifolium), Carne de vaca (Clethra
\end{abstract}


scabra) and Farinha seca (Albizia hasslerii). The initial and non-pioneer secondary species planted among the pioneer species were, respectively, the Yellow Ipê (Tabebuia ocharea) and the Jatobá (Hymenaea courbaril), these species being used for the subareas. After 449 days the survival rate of the pioneer and non-pioneer species for subareas 1 and 2 was evaluated. In general, there was no effect of liming on plant survival. For subarea 1, the species with the highest survival rate was Pau Ferro. For subarea 2, the species with the highest survival rate was Gonçalo Alves. Subarea 1 presented a higher survival rate of non-pioneer species than subarea 2.

Keywords: Erosion; Cerrado; Acidity; Reforestation.

\section{Resumen}

El objetivo de este estudio fue evaluar la tasa de supervivencia de especies nativas del cerrado en función del encalado. El experimento se llevó a cabo en una microcuenca del río Pandeiros. El área experimental tuvo suelos con bajo $\mathrm{pH}$, baja saturación de bases y fuertes signos de degradación antropogénica. Se plantaron especies forestales nativas pioneras y no pioneras en el área de préstamo río arriba de las terrazas construidas con el propósito de contener la erosión, probando la ausencia y presencia de calizas dolomíticas en los pozos de siembra. La siembra se realizó en dos subzonas dentro de la microcuenca. Para la subárea 1, las especies pioneras ensayadas fueron Angico Vermelho (Anadenanthera macrocarpa), Aroeira (Lithraea molleoides) y Pau Ferro (Caesalpinia ferrea); en la subzona 2, las especies analizadas fueron: Gonçalo Alves (Astronium fraxinifolium), Carne de vacuno (Clethra scabra) y Harina seca (Albizia hasslerii). Las especies iniciales secundarias y no pioneras plantadas entre las pioneras fueron, respectivamente, Ipe amarillo (Tabebuia ocharea) y Jatobá (Hymenaea courbaril), siendo estas especies las que se utilizan para las subzonas. Después de 449 días, se evaluó la tasa de supervivencia de las especies pioneras y no pioneras para las subáreas 1 y 2 . En general, no hubo efecto del encalado sobre la supervivencia de las plantas. Para la subzona 1, la especie con mayor tasa de supervivencia fue Pau Ferro. Para la subzona 2, la especie con mayor tasa de supervivencia fue Gonçalo Alves. La subárea 1 tuvo una mayor tasa de supervivencia de especies no pioneras que la subárea 2.

Palabras clave: Erosión; Cerrado; Acidez; Reforestación.

\section{Introdução}

O cerrado brasileiro abriga uma grande quantidade de espécies nativas da fauna e da flora. Todavia, apesar da sua importância para conservação da biodiversidade, uma série de práticas insustentáveis e falhas na fiscalização e na legislação ambiental em tempos passados e atuais, contribuíram e contribuem para sua deterioração.

Entre essas práticas pode-se citar o desmatamento da vegetação nativa para produção de carvão (Costa et al., 2014), o número excessivo de operações no preparo do solo (Carneiro et al., 2009; Lourente et al., 2011), a ausência de estratégias de manejo da fertilidade do solo ou a sua realização de maneira incorreta, tal como a não realização da calagem ou sua utilização em doses excessivas (Frazão et al., 2008). Os efeitos nocivos dessas práticas são mais expressivos em solos que apresentam alto grau de fragilidade, como os Neossolos, que ocupam grande extensão do território brasileiro (Donagemma et al., 2016).

Os Neossolos ocupam aproximadamente 13,18\% do território brasileiro, sendo a terceira classe mais abundante, são distinguíveis no Sistema Brasileiro de Classificação de Solos - SIBCS pela textura arenosa - ou seja, classes texturais areia ou areia franca - em todos os horizontes, até a profundidade de 1,50 m da superfície do solo, ou até o contato lítico (Embrapa, 2013).

As limitações de natureza física normalmente apresentadas nesses solos são a drenagem excessiva e baixa retenção de água, devido à baixa presença de microporos comparativamente a solos de granulometria mais fina. Como limitações de natureza química os Neossolos podem apresentar teores tóxicos de $\mathrm{Al}^{3+}$, baixo $\mathrm{pH}$ e baixa disponibilidade de nutrientes e matéria orgânica (Donagemma et al., 2016).

Para suplantar essas limitações a adoção de práticas vegetativas, tal como o plantio de espécies herbáceas e o reflorestamento com espécies nativas e a adoção de práticas edáficas, tais como o controle das queimadas, adubação e a calagem normalmente apresentam resultados satisfatórios (Frazão et al., 2008; Ikeda et al., 2008). Contudo, em situações mais severas de degradação, como na presença de voçorocas, podem ser requeridas práticas de múltiplo caráter, como as mecânicas (construção de barraginhas e terraços), onerando os custos de recuperação ambiental. 
Voçorocas constituem o estágio mais avançado dos processos erosivos, ocasionando a perda de solo com consequente prejuízo financeiro, social e ambiental (Morais et al., 2004; Guglieri-Caporal et al., 2011; Tedesco et al., 2014). Nessa situação, a realização de práticas mecânicas torna-se evidente, aumentando os custos de controle. Além disso, no processo de construção de estruturas em áreas de mata fechada, pode haver algum impacto na vegetação existente, evidenciando a recomposição da cobertura vegetal.

Consoante Marques et al. (2014), a escolha da espécie vegetal na recuperação de áreas degradadas é primordial, devendo-se priorizar aquelas com capacidade de desenvolvimento em condições de baixa disponibilidade de água e nutrientes. Além disso, o arranjo espacial dessas plantas e o uso de espécies com diferentes hábitos e taxa de crescimento, é importante no sentido de se buscar a máxima cobertura do solo e uma melhor exploração das raízes no perfil do solo.

Song et al. (2016) destacam que o cultivo de espécies florestais em terrenos arenosos semiáridos desempenha um papel importante na prevenção e controle da desertificação. Todavia, conforme se depreende do trabalho de Valdes-Rodriguez et al. (2011), em solos de textura franco-arenosa e textura arenosa, a exemplo dos Neossolos, a adoção de práticas planejadas de fertilização mineral são fundamentais para a garantia do bom desenvolvimento das plantas. Nesse panorama a calagem apresenta-se como técnica relativamente barata de conservação ou melhoria da qualidade do solo, possibilitando vantagens como a neutralização do $\mathrm{Al}^{3+}$, a elevação do $\mathrm{pH}$ e o fornecimento de $\mathrm{Ca}$ e $\mathrm{Mg}$, e a disponibilização de nutrientes que possam vir a favorecer o desenvolvimento das plantas.

Dessa maneira objetivou-se avaliar o efeito da calagem na cova de plantio para a sobrevivência de espécies nativas do cerrado em área degradada na bacia do rio Pandeiros.

\section{Metodologia}

A área de estudo localiza-se nas coordenadas centrais de Longitude 479107 E e Latitude 8318800 S (projeção UTM), com clima Aw segundo classificação de Köppen (Alvares et al., 2013), a montante da Pequena Central Hidrelétrica (PCH) Pandeiros, próximo ao distrito de Várzea Bonita, Januária-MG. O levantamento de solos utilizou como base o mapa de solos de Minas Gerais, sendo validado com visitas a campo. As classes de solo predominantes na microbacia em estudo são o Neossolo Quartzarênico órtico típico (RQo), dominando as regiões elevadas da paisagem, formada a partir dos arenitos do Grupo Urucuia e, o Neossolo Litólico Distrófico típico (RLd) nas maiores declividades, associando-se com RQo. Considerada num aspecto geral, predomina na paisagem o bioma cerrado, fragilizado pela remoção ou dano à cobertura vegetal nativa. Essa depreciação está atribuída principalmente à exploração do cerrado para carvão nas décadas de 1970 e 80, associadas à pecuária extensiva sobre solos de fertilidade limitada com baixa reserva de nutrientes e pH, o que intensificou a erosão laminar e voçorocamentos ativos, e assim aumentando a pressão sobre as veredas.

O experimento iniciou em 14 de fevereiro de 2017 com a abertura de covas de plantio na área que foi utilizada para empréstimo de material para construção do camalhão de terraços à montante de voçorocas ativas localizadas em duas subáreas na bacia do rio Pandeiros. As coordenadas centrais (projeção UTM) dessas subáreas foram: Latitude 8318823,14S e Longitude 479098,93 para a subárea 1, e Latitude $8319013,04 \mathrm{~S}$ e Longitude 479835,97 E para a subárea 2. As duas subáreas apresentaram declividades de aproximadamente $5 \%$, com altitude média de $670 \mathrm{~m}$.

Na Tabela 1 são apresentados os atributos químicos e físicos do solo antes da implantação do experimento, em que se evidencia os baixos valores de $\mathrm{pH}$, a baixa saturação por bases $(\mathrm{V})$, a elevada saturação por alumínio tóxico $\left(\mathrm{Al}^{3+}\right)$ e os baixos teores de matéria orgânica para as duas subáreas, conferindo baixa fertilidade natural ao solo, agravada pela textura arenosa que condiciona baixa retenção de água. Nessas condições fica explícita a alta fragilidade ambiental e baixa aptidão agrícola do solo em questão. 
Tabela 1. Atributos químicos e físicos do solo em área experimental na bacia do rio Pandeiros.

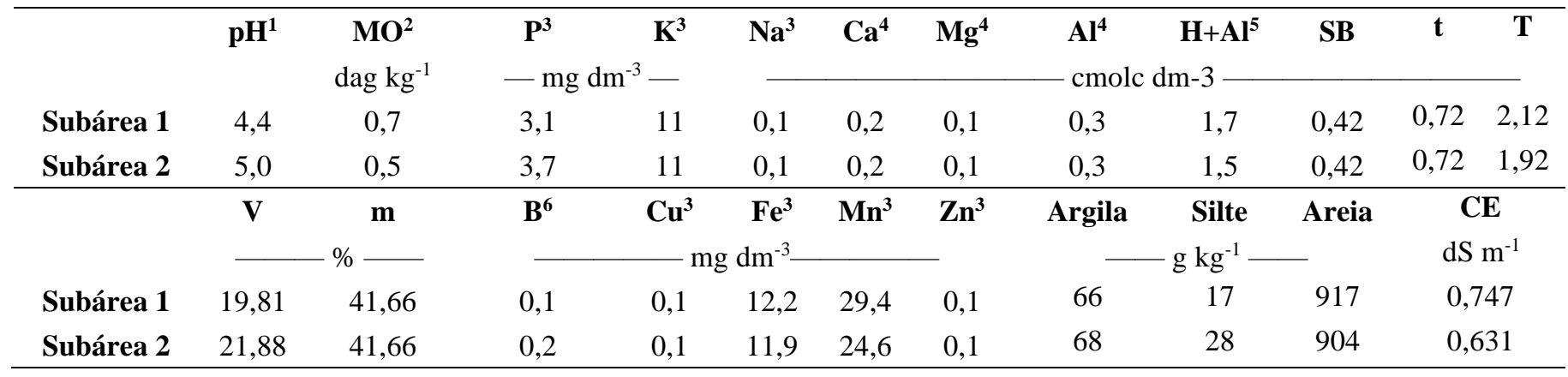

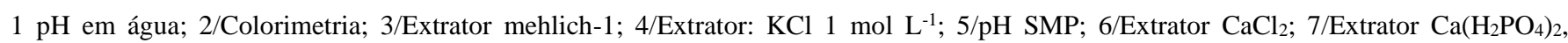
500mg/L de P em HOAc 2mol/L; 8/Solução equilíbrio de P; SB, Soma de bases; t, CTC efetiva; T, CTC a pH 7; V, Saturação por bases; m, Saturação por alumínio; CE, condutividade elétrica. Fonte: Autores.

As covas de plantios foram abertas com 40 x $40 \mathrm{~cm}$ (diâmetro x profundidade), onde receberam adubo NPK 4-14-18 na dose de $150 \mathrm{~g} \mathrm{cova}^{-1}$. O calcário utilizado nas parcelas que o receberam apresentou $104 \%$ de PRNT, $38 \%$ de CaO e $17 \%$ de $\mathrm{MgO}$, sendo utilizada a dose de $200 \mathrm{~g} \mathrm{cova}^{-1}$, seguindo recomendação sugerida por Aquino et al. (2009).

As espécies utilizadas foram classificadas como pioneiras, secundária inicial e não pioneiras (ou clímax) (Budowski, 1965). O plantio iniciou-se em 15 de fevereiro de 2017 adotando-se o sistema de cultivo em Quincôncio, nesse sistema cada muda de espécie não-pioneira (ou a secundária inicial) se encontra posicionada no centro de quatro mudas de espécies pioneiras. As plantas pioneiras foram distanciadas de 2,5 x 2,5 m, conforme o esquema apresentado na Figura 1. As mudas foram provenientes de doações do viveiro do Instituto Estadual de Florestas (IEF) - Janaúba-MG e do viveiro do Centro de Recuperação de Áreas Degradadas (CRAD) - Janaúba-MG. Para evitar a entrada de bovinos nas subáreas e os consequentes danos as plantas que poderiam vir a causar, foram construídas cerca de arame liso e mourões de eucalipto tratado no entorno das duas subáreas.

Figura 1. Esquema ilustrativo da disposição das plantas no campo em experimento de sobrevivência de espécies nativas do Cerrado em função da calagem. Várzea Bonita, Januária-MG.

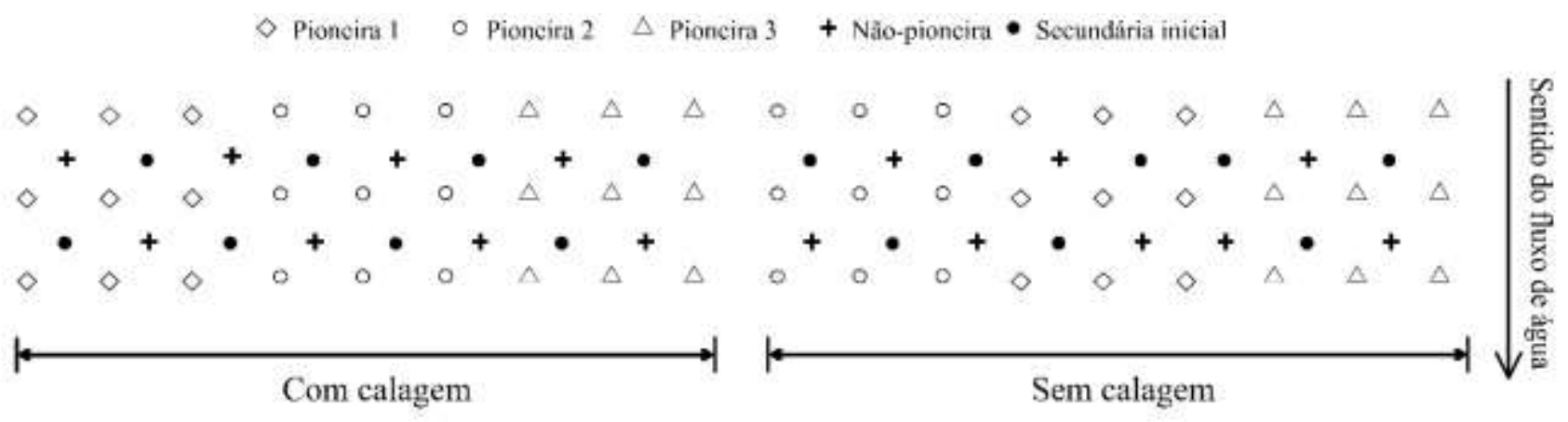

\section{Terraço}

Fonte: Autores.

Em 10 de maio de 2018 (449 dias após o plantio) foi realizada a avaliação de sobrevivência das espécies pioneiras e não pioneiras nas unidades experimentais, para tanto, contabilizou-se o número de plantas vivas pertencentes a cada grupo ecofisiológico dentro de cada unidade experimental, posteriormente calculou-se a quantidade relativa de plantas vivas, obtendo-se os índices de sobrevivência de plantas pioneiras (ISP) e de espécies não pioneiras (ISNP). As unidades 
experimentais foram compostas por nove plantas para avaliação do ISP e oito plantas para avaliação do ISNP, conforme esquema ilustrativo na Figura 1.

Para avaliação do índice de sobrevivência de espécies pioneiras (ISP) o delineamento experimental utilizado foi o de blocos casualizados (sendo os blocos alocados na área a montante de cada terraço), com o arranjo de parcelas subdivididas (2x3), sendo o fator nas parcelas a ausência e a presença do calcário. Já o fator na subparcela foi o plantio de três espécies nativas arbóreas classificadas como pioneiras segundo a classificação de Budowski (1965). Esse experimento foi conduzido utilizando-se espécies distintas para cada subárea. Para a subárea 1, as espécies testadas foram o Angico Vermelho (Anadenanthera macrocarpa), Aroeira (Lithraea molleoides) e Pau Ferro (Caesalpinia ferrea); já para a subárea 2 as espécies testadas foram: Gonçalo Alves (Astronium fraxinifolium), Carne de Vaca (Clethra scabra) e Farinha Seca (Albizia hasslerii).

As espécies utilizadas referentes aos grupos ecofisiológicos secundária inicial e não-pioneira plantadas entre as espécies pioneiras foram respectivamente o Ipê Amarelo (Tabebuia ocharea) e o Jatobá (Hymenaea courbaril), sendo utilizadas essas espécies para as subáreas 1 e 2.

A avaliação do índice de sobrevivência das espécies não-pioneiras (ISNP) foi realizada de maneira conjunta para as subáreas 1 e 2, uma vez que foi utilizada a mesma espécie, o jatobá (Hymenaea courbaril). O delineamento foi em blocos casualizados e os tratamentos consistiram da presença ou da ausência de calagem. Todas as análises estatísticas foram realizadas no software R (R Core Team, 2021). Não foi possível a avaliação das espécies classificadas como secundária inicial, uma vez que na época de avaliação todas as plantas tinham morrido.

Os dados de precipitação $(\mathrm{mm})$ e temperatura $\left({ }^{\circ} \mathrm{C}\right)$ do período compreendido entre o plantio e a avaliação de sobrevivência das plantas são apresentados na Figura 2.

Figura 2. Precipitação (mm) e temperatura média $\left({ }^{\circ} \mathrm{C}\right)$ entre 15/02/2017 e 10/05/2018 em uma microbacia do rio Pandeiros. Dados obtidos em uma estação Meteorológica instalada na área experimental.

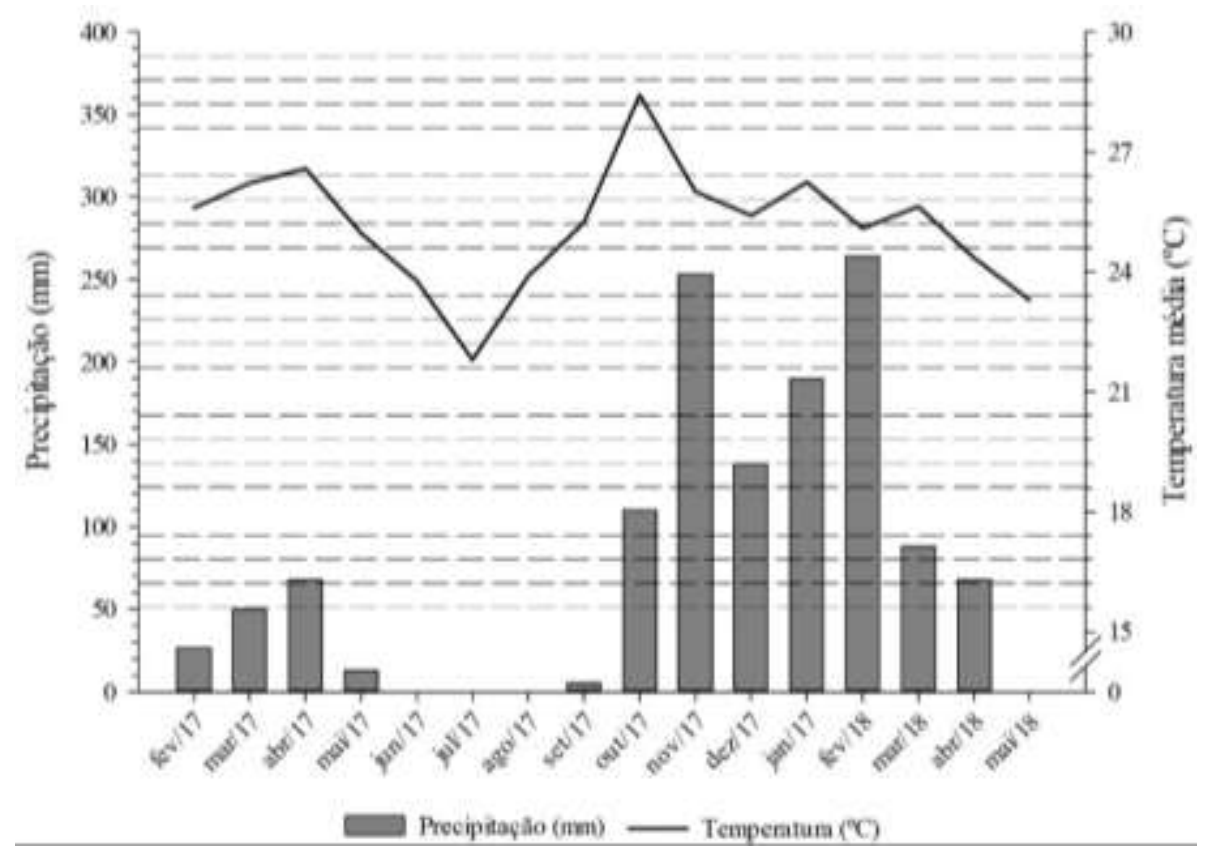

Fonte: Autores.

\section{Resultados e discussão}

A análise de variância para os dados de índice de sobrevivência de plantas pioneiras (ISP) indicou que não houve interação dos fatores calagem (C) e espécies (E) para nenhuma das subáreas dentro da bacia, entretanto, foi verificado efeito 
isolado das espécies (E) para as duas subáreas da bacia (Tabela 2). Não foi verificado nenhum efeito em relação à realização da calagem.

Tabela 2. Resumo da análise de variância para o índice de sobrevivência espécies pioneiras (ISP) em função da realização ou não de calagem em duas subáreas em uma microbacia do rio Pandeiros.

\begin{tabular}{|c|c|c|c|c|c|}
\hline \multirow{2}{*}{ FV } & \multirow{2}{*}{ GL } & \multicolumn{2}{|c|}{ ISP Área 1} & \multicolumn{2}{|c|}{ ISP Área 2} \\
\hline & & $\mathbf{Q M}$ & $\operatorname{Pr}(>\mathrm{Fc})$ & $\mathbf{Q M}^{/ 1}$ & $\operatorname{Pr}(>$ Fc) \\
\hline Calagem (C) & 1 & 109,7 & 0,6039 & 871,70 & 0,22591 \\
\hline Espécie (E) & 2 & 5028,2 & $7,8 \mathrm{E}-05$ & 1433,83 & 0,04096 \\
\hline Bloco & 2 & 1447,3 & 0,1693 & 447,33 & 0,39456 \\
\hline $\mathrm{C} \times \mathrm{E}$ & 2 & 6,9 & 0,9491 & 570,83 & 0,20461 \\
\hline Erro 1 & 2 & 294,9 & & 291,52 & \\
\hline Erro 2 & 8 & 130,3 & & 293,12 & \\
\hline CV1 (\%) & & 32,35 & & 118,48 & \\
\hline CV2 (\%) & & 21,51 & & 118,81 & \\
\hline
\end{tabular}

${ }^{11}$ Para análise, os dados de ISP da área 2 foram transformados em ARCSEN $(\mathrm{X})^{0,5}$. (FV) Fonte de Variação; (GL) Graus de liberdade; (QM) Quadrados Médios; $\operatorname{Pr}(>\mathrm{Fc})$ Significância do teste F. Fonte: Autores.

Para que as reações do calcário ocorram é necessária uma condição mínima de umidade no solo, embora, segundo Bortoluzzi et al. (2008), a realização da técnica altera a relação entre solo e água, tornando o solo mais hidrófilo com o aumento das doses de calcário. Todavia, dada à baixa capacidade de retenção de água do solo em questão (condutividade Hidráulica do Solo saturado $=100,8 \mathrm{~mm} \mathrm{~h}^{-1}$ ) é possível que o solo não tenha se mantido úmido o suficiente para que as reações do calcário no solo se processassem. Sobretudo em virtude da não realização de irrigação e da expressiva redução e cessamento da precipitação evidenciada entre o terceiro e sexto mês após a realização da calagem, conforme se observa na Figura 2.

Silva et al. (2011), avaliando o desenvolvimento inicial de espécies exóticas e nativas e necessidade de calagem em área degradada com ocorrência de voçorocas no cerrado do triângulo mineiro (MG), verificaram que o uso de calcário é dispensável na fase inicial de crescimento das plantas.

De modo contrário ao observado no presente trabalho, Scheer et al. (2017), avaliando o crescimento inicial de quatro espécies florestais nativas em área degradada, verificaram que a dose de $250 \mathrm{~g}$ de calcário por cova possibilitou, na maioria dos casos, o melhor desenvolvimento das espécies utilizadas no experimento. Esses autores mencionaram ainda que o uso de doses de 500 g de calcário por cova, em algumas situações, afetou o crescimento das plantas, provavelmente em função do aumento excessivo de $\mathrm{pH}$ e consequente diminuição da disponibilidade de micronutrientes catiônicos e/ou pelo desbalanço nutricional ocasionado.

Para a subárea 1 verificou-se que a espécie pioneira com maior índice de sobrevivência (ISP) foi o Pau Ferro, com 79,63\% de sobrevivência, seguida da Aroeira e do Angico Vermelho, com 57,41 e 22,22\% de ISP, respectivamente (Tabela 3). De acordo Lima et al. (2008), o Pau Ferro (Caesalpinia ferrea) apresenta ajustamentos morfológicos e fisiológicos importantes em relação ao aproveitamento da luz que potencializam o seu crescimento e desenvolvimento, o que possivelmente explica seu maior índice de sobrevivência nas condições desse trabalho. 
Tabela 3. Índice de sobrevivência de espécies pioneiras (ISP) em duas subáreas em uma microbacia do rio Pandeiros.

\begin{tabular}{|c|c|c|c|}
\hline \multicolumn{2}{|c|}{$\longrightarrow$ Área $1 \longrightarrow$} & \multicolumn{2}{|c|}{$\longrightarrow$ Área 2} \\
\hline Espécie & $\operatorname{ISP}(\%)$ & Espécie & ISP $(\%)$ \\
\hline Angico Vermelho & $22,22 \mathrm{c}$ & Farinha seca & $1,85 \mathrm{~b}$ \\
\hline Aroeira & $57,41 \mathrm{~b}$ & Carne de vaca & $5,55 \mathrm{ab}$ \\
\hline Pau Ferro & $79,63 \mathrm{a}$ & Gonçalo Alves & $29,62 \mathrm{a}$ \\
\hline
\end{tabular}

Médias seguidas de mesma letra nas colunas não diferem entre si pelo teste de Tukey ao nível de 5\% de significância. Fonte: Autores.

Para a subárea 2, a espécie com maior potencial de sobrevivência foi o Gonçalo Alves, com 29,62\% de sobrevivência, seguida da Carne de Vaca e da Farinha seca, com 5,55 e 1,85 \% de ISP, respectivamente (Tabela 3). Embora as espécies testadas tenham sido diferentes para subáreas 1 e 2, ressalta-se o pior desempenho para a maioria das espécies na subárea 2, o que indica para o fator cobertura do solo, maior contribuição para a ocorrência dos processos erosivos nessa subárea, comparativamente a subárea 1.

A análise conjunta indicou que não houve efeito significativo dos tratamentos testados sobre do índice de sobrevivência da espécie não pioneira (ISNP), no caso, o Jatobá (Tabela 4). Contudo, sendo verificadas diferenças no ISNP para as áreas 1 e 2, cujos valores foram 54,17 \% e 18,75\% respectivamente (Tabela 5). De acordo Lorenzi et al. (2009), o jatobá é indicado para a recuperação de áreas degradadas, uma vez que é bastante procurada pela fauna. Essas diferenças possivelmente decorrem de um maior teor matéria orgânica na subárea 1, cujo valor é 40\% maior que na subárea 2 . A respeito da importância da matéria orgânica do solo, ela exerce melhorias dos atributos químicos com o aumento da capacidade de troca catiônica (CTC), melhorias nos atributos biológicos e, também, nos atributos físicos, como por exemplo aumento da retenção hídrica do solo (Soares et al., 2019; Salomão et al., 2020; Oliveira et al., 2021).

Tabela 4. Resumo da análise de variância conjunta para o índice de sobrevivência espécies não pioneiras (ISNP) em função da realização ou não da calagem em duas subáreas em uma microbacia do rio Pandeiros.

\begin{tabular}{cccc}
\hline FV & GL & QM & Pr(>Fc) \\
\hline Bloco (Area) & 4 & 638,020833 & 0,0648 \\
Área (A) & 1 & 3763,020833 & 0,0048 \\
Calagem (C) & 1 & 117,187500 & 0,3739 \\
A x C & 1 & 117,187500 & 0,3739 \\
Erro & 4 & 117,187500 & \\
\hline
\end{tabular}

$$
\text { CV }(\%)
$$

29,69

(FV) Fonte de Variação; (GL) Graus de liberdade; (QM) Quadrados Médios; $\operatorname{Pr}(>\mathrm{Fc}$ ) Significância do teste F a 5\% de probabilidade. Fonte: Autores.

Tabela 5. Índice de sobrevivência de espécies não pioneiras (ISNP) em duas subáreas em uma microbacia do rio Pandeiros.

\begin{tabular}{cc}
\hline Área & ISNP (\%) \\
\hline 1 & $54,17 \mathrm{a}$ \\
2 & $18,75 \mathrm{~b}$ \\
\hline
\end{tabular}

Médias seguidas de mesma letra nas colunas não diferem entre si pelo teste de Tukey ao nível de 5\% de significância. Fonte: Autores. 
Observa-se então que a espécie pioneira com maior índice de sobrevivência em cada subárea apresentou maior índice que a espécie não pioneira para a respectiva subárea. Isso possivelmente é explicado pela maior dificuldade de estabelecimento das espécies não pioneiras a pleno sol, tendo em vista a área estar bastante degradada. Almeida (2016) relata que classificação das espécies em grupos ecofisiológicos permite agrupar as espécies com características sucessionais similares, dando uma ideia do comportamento das diversas espécies no ecossistema. Atinentes as várias classificações ecofisiológicas existentes, Santos et al. (2004) mencionam que no geral as divisões se baseiam na exigência de luz pelas espécies, de maneira que aquelas mais exigentes ou mais tolerantes são indicadas para os momentos iniciais da sucessão, de modo contrário, as espécies menos tolerantes ou menos exigentes são indicadas para os momentos mais tardios.

O desdobramento do efeito de blocos para a análise conjunta do ISNP indicou que na área 1 o bloco correspondente ao terraço superior apresentou menor índice de sobrevivência que os demais terraços, conforme se verifica na Tabela 6 . Para a área 2 não foram verificadas diferenças no índice de sobrevivência entre os terraços. Possivelmente, o menor índice de sobrevivência no terraço superior da área 1 seja explicada pela ocorrência de erosão mais acentuada nas áreas de empréstimo à montante desse terraço, uma vez que a área de contribuição é maior para esse terraço, culminando no carreamento de nutrientes para o canal do terraço. Os terraços inferiores, uma vez protegidos, sofrem assim menor impacto da erosão, tendo em vista uma menor área de contribuição.

Tabela 6. Índice de sobrevivência de espécies não pioneiras (ISNP) em duas subáreas em uma microbacia do rio Pandeiros.

\begin{tabular}{ccc}
\hline Bloco & & ISNP (\%) \\
\cline { 2 - 3 } & Subárea 1 & Subárea 2 \\
\hline Terraço inferior & $68,75 \mathrm{aA}$ & $18,75 \mathrm{aB}$ \\
Terraço mediano & $68,75 \mathrm{aA}$ & $18,75 \mathrm{aB}$ \\
Terraço superior & $25,00 \mathrm{bA}$ & $18,72 \mathrm{aA}$ \\
\hline
\end{tabular}

Médias seguidas de mesma letraminúscula nas colunas e médias seguidas de mesma letra maiúscula nas linhas não diferem entre si pelo teste de Tukey ao nível de 5\% de significância. Fonte: Autores.

Apesar do maior potencial individual de sobrevivência de uma espécie ou de outra para as subáreas consideradas, observa-se que no geral houve um baixo índice de sobrevivência das espécies. Essa dificuldade de sobrevivência é um fator limitante para a recuperação das áreas de degradadas e para a conservação do solo e da água na bacia do rio Pandeiros, uma vez que a cobertura vegetal é um fator intimamente ligado a erosão do solo. Em parte, essa baixa sobrevivência é explicada pelas características químicas, tais como baixo $\mathrm{pH}$, baixo teor de matéria orgânica e, das características físicas, principalmente a granulometria do solo, conferindo baixa retenção de água.

Segundo Lima et al. (2015), as taxas de sobrevivência de mudas variam muito de acordo com as condições ambientais, principalmente com a precipitação nos anos subsequentes ao plantio. Nesse sentindo, outro ponto que pode ter contribuído para os baixos índices de sobrevivência foi a sazonalidade da estação chuvosa, pois mesmo tendo chovido 1273 $\mathrm{mm}$ no período considerado, as maiores precipitações aconteceram de maneira concentrada entre os meses de outubro a fevereiro, também, as altas temperatura no verão, conforme se verifica na Figura 2. Dessa forma, ressalta-se a importância da preservação da cobertura vegetal já existente e da recomposição com espécies nativas.

O baixo índice de sobrevivência das espécies testadas evidencia a necessidade de se buscar estratégias mais eficientes que possam ser utilizadas em projetos de recuperação de áreas degradadas na bacia do rio Pandeiros. 


\section{Conclusões}

A realização da calagem na cova de plantio, nas condições desse estudo, não condiciona maior sobrevivência de plantas pioneiras ou não pioneiras. Entretanto, sugere-se a realização de outros estudos, especialmente com doses diferentes das testadas nesse trabalho.

Para as respectivas subáreas que foram plantadas, as espécies com maior potencial de sobrevivência na bacia do rio Pandeiros são o Pau Ferro (79,63\%), a Aroeira (57,41\%) e o Gonçalo Alves (29,62\%).

\section{Agradecimentos}

Realizado com apoio da Fundação de Amparo à Pesquisa do Estado de Minas Gerais - FAPEMIG, Processo N.: CAG - APQ-03775-14, Projeto: "Quantificação, monitoramento e controle da erosão na bacia do rio Pandeiros".

O presente trabalho foi realizado com apoio da Coordenação de Aperfeiçoamento de Pessoal de Nível Superior Brasil (CAPES) - Código de Financiamento 001.

\section{Referências}

Almeida, D. S. (2016). Alguns princípios de sucessão natural aplicados ao processo de recuperação. In: Recuperação ambiental da Mata Atlântica. http://books.scielo.org/id/8xvf4/pdf/almeida-9788574554402-06.pdf.

Alvares, C. A., Stape, J. L., Sentelhas, P. C., Gonçalves, J. D. M., \& Sparovek, G. (2013). Köppen’s climate classification map for Brazil. Meteorologische Zeitschrift, 22(6), 711-728.

Aquino, F. G., Oliveira, M. C., Ribeiro, J. F., \& Passos, F. B. (2009). Módulos para recuperação de Cerrado com espécies nativas de uso múltiplo. https://ainfo.cnptia.embrapa.br/digital/bitstream/CPAC-2010/31916/1/doc-250.pdf.

Bortoluzzi, E. C., Garbozza, L., Guareschi, C., \& Rheinheimer, D. D. S. (2008). Efeito da calagem na relação entre solo e água. Revista Brasileira de Ciência do Solo, 32(spe), 2621-2628. https://doi.org/10.1590/s0100-06832008000700003.

Budowski, G. N. (1965). Distribution of tropical American rain forest species in the light of succession processes. Turrialba.

Carneiro, M. A. C., Souza, E. D. de, Reis, E. F. dos, Pereira, H. S., \& Azevedo, W. R. de. (2009). Atributos físicos, químicos e biológicos de solo de cerrado sob diferentes sistemas de uso e manejo. Revista Brasileira de Ciência do Solo, 33(1), 147-157. https://doi.org/10.1590/s0100-06832009000100016.

Costa, T. G., Bianchi, M. L., Protásio, T. de P., Trugilho, P. F., \& Pereira, A. J. (2014). Qualidade da madeira de cinco espécies de ocorrência no cerrado para produção de carvão vegetal. CERNE, 20, 37-46. https://doi.org/10.1590/S0104-77602014000100005.

Donagemma, G. K., de Freitas, P. L., de Carvalho Balieiro, F., Fontana, A., Spera, S. T., Lumbreras, J. F., Viana, J. H. M., de Araújo Filho, J. C., dos Santos, F. C., \& de Albuquerque, M. R. (2016). Caracterização, potencial agrícola e perspectivas de manejo de solos leves no Brasil. Pesquisa Agropecuária Brasileira, 51(9), 1003-1020. https://www.scielo.br/j/pab/a/HQcWhPqMBK43vSgQdgctnBc/?lang=pt\&format=pdf.

EMBRAPA - Empresa Brasileira de Pesquisa Agropecuária. (2017). Manual de métodos de análises de solos. (3a ed.), Embrapa Solos. 574 p.

EMBRAPA - Empresa Brasileira de Pesquisa Agropecuária. (2018). Sistema brasileiro de classificação de solos. (5a ed.), 356p.

Frazão, L. A., Píccolo, M. de C., Feigl, B. J., Cerri, C. C., \& Cerri, C. E. P. (2008). Propriedades químicas de um Neoss olo Quartzarênico sob diferentes sistemas de manejo no Cerrado mato-grossense. Pesquisa Agropecuária Brasileira, 43(5), 641-648. https://doi.org/10.1590/S0100-204X2008000500012.

Guglieri-Caporal, A., Caporal, F. J. M., Pott, A., Vinci-Carlos, H. C., \& Morales, C. A. S. (2011). Revegetação espontânea de voçoroca na região de Cerrado, Mato Grosso do Sul, Brasil. Hoehnea, 38, 289-306. https://doi.org/10.1590/S2236-89062011000200009.

Ikeda, F. S., Mitja, D., Vilela, L., \& Silva, J. C. S. (2008). Banco de sementes em cerrado sensu stricto sob queimada e sistemas de cultivo. Pesquisa Agropecuária Brasileira, 43(6), 667-673. https://doi.org/10.1590/S0100-204X2008000600001.

Lima, J. D., Silva, B. M. da S. e, Moraes, W. da S., Dantas, V. A. V., \& Almeida, C. C. (2008). Efeitos da luminosidade no crescimento de mudas de Caesalpinia ferrea Mart. Ex Tul. (Leguminosae, Caesalpinoideae). Acta Amazonica, 38, 5-10. https://doi.org/10.1590/S0044-59672008000100002.

Lima, M. M. de, Santos, L. de A., Moura, F. de B. P., \& de Souza Nogueira, E. M. (2015). Sobrevivência inicial de seis espécies usadas na recuperação de uma área degradada na caatinga. Revista Ouricuri, 5(2), 132-137. https://www.revistas.uneb.br/index.php/ouricuri/article/view/1489/979.

LORENZI, H. Árvores brasileiras: manual de identificação e cultivo de plantas arbóreas nativas do Brasil. (3a ed.), Plantarum, v.2, 384p., 2009.

Lourente, E. R. P., Mercante, F. M., Alovisi, A. M. T., Gomes, C. F., Gasparini, A. S., \& Nunes, C. M. (2011). Atributos microbiológicos, químicos e físicos de solo sob diferentes sistemas de manejo e condições de cerrado. Pesquisa Agropecuária Tropical, 41, 20-28. https://doi.org/10.5216/pat.v41i1.8459. 
Marques, T. E. D., Baêta, H. E., Leite, M. G. P., Martins, S. V., \& Kozovits, A. R. (2014). Crescimento de espécies nativas de Cerrado e de Vetiveria zizanioides em processos de revegetação de voçorocas. Ciência Florestal, 24, 843-856. http://dx.doi.org/10.5902/1980509816584.

Morais, F., Bacellar, L. A. P., \& Sobreira, F. G. (2004). Análise da erodibilidade de saprolitos de gnaisse. Revista Brasileira de Ciência do Solo, 28, 10551062. https://doi.org/10.1590/S0100-06832004000600014.

Oliveira, L. L. P., Portela, J. C., Silva, E. F., Dias, N. S., Gondim, J. E. F., Fernandes, C. N., \& Medeiros, J. F. (2021). Water retention in Cambisols under land uses in semiarid region of the Brazil. Journal of Arid Environments, 189, 104483. https://doi.org/10.1016/j.jaridenv.2021.104483

R Core Team. (2021). R: A language and environment for statistical computing.R Foundation for Statistical Computing. https://www.Rproject.org/.

Salomão, P. E. A., Kriebel, W., dos Santos, A. A., \& Martins, A. C. E. (2020). A importância do sistema de plantio direto na palha para reestruturação do solo e restauração da matéria orgânica. Research, Society and Development, 9(1), e154911870-e154911870. https://doi.org/10.33448/rsd-v9i1.1870

Santos, J. H. da S., Ferreira, R. L. C., Silva, J. A. A. da, Souza, A. L. de, Santos, E. de S., \& Meunier, I. M. J. (2004). Distinção de grupos ecológicos de espécies florestais por meio de técnicas multivariadas. Revista Árvore, 28, 387-396. https://doi.org/10.1590/S0100-67622004000300010.

Scheer, M. B., Carneiro, C., Bressan, O. A., \& dos Santos, K. G. (2017). Crescimento inicial de quatro espécies florestais nativas em área degradada com diferentes níveis de calagem e de adubação. FLORESTA, 47(3), 279-287. http://dx.doi.org/10.5380/rf.v47i3.41973.

Silva, A. H. da, Pereira, J. S., \& Rodrigues, S. C. (2011). Desenvolvimento inicial de espécies exóticas e nativas e necessidade de calagem em área degradada do Cerrado no triângulo mineiro (Minas Gerais, Brasil). Agronomía Colombiana, 29(2), 479-484. https://www.redalyc.org/articulo.oa?id=180322766014.

Soares, D. dos S., Ramos, M. L. G., Marchão, R. L., Maciel, G. A., Oliveira, A. D. de, Malaquias, J. V., \& Carvalho, A. M. de. (2019). How diversity of crop residues in long-term no-tillage systems affect chemical and microbiological soil properties. Soil and Tillage Research, 194 , 104316. https://doi.org/10.1016/j.still.2019.104316

Song, L., Zhu, J., Li, M., \& Zhang, J. (2016). Water use patterns of Pinus sylvestris var. mongolica trees of different ages in a semiarid sandy lands of Northeast China. Environmental and Experimental Botany, 129, 94-107. https://doi.org/10.1016/j.envexpbot.2016.02.006.

Tedesco, A., Antunes, A. F. B., \& Oliani, L. O. (2014). Detecção de formação erosiva (voçoroca) por meio de classificação hierárquica e por árvore de decisão. Boletim de Ciências Geodésicas, 20(4), 1005-1026. https://doi.org/10.1590/s1982-21702014000400055.

Valdes-Rodriguez, O. A., Sánchez-Sánchez, O., Pérez-Vázquez, A., \& Ruiz-Bello, R. (2011). Soil texture effects on the development of Jatropha seedlings Mexican variety 'piñón manso'. Biomass and Bioenergy, 35(8), 3529-3536. https://doi.org/10.1016/j.biombioe.2011.05.003. 